\title{
ATP Metabolism as Biomarker Target for Cardiovascular Protection
}

\section{Pollen K Yeung*}

Dalhousie University, Canada

Cardiovascular disease including stroke is the leading cause of death and disability worldwide and an enormous economic burden to our societies [1]. Based on the latest statistics released for heart and stroke disease, an estimated 83,600,000 adults in the United States (US) (>30\%) have one or more types of Cardiovascular Disease (CVD) of whom more than $90 \%$ have hypertension, $18 \%$ have Coronary Heart Disease (CHD), close to $10 \%$ have Myocardial Infarction (MI) and $8 \%$ have stroke. The total direct and indirect cost in the US alone for treatment of cardiovascular diseases (hospitalization, drugs, home healthcare, etc.) and lost of productivity and morbidity is estimated at close to $\$ 315$ billion US per year [2]. Thus prevention by better diagnosis and drug treatment could provide a huge saving for the health care cost worldwide. Despite advancement in modern cardiovascular medicine, the prevalence of hypertension, Ischemic Heart Disease (IHD) and stroke is still on the rise, and that finding an optimum therapy to slow disease progression remains a therapeutic challenge.

In our laboratory, we have been embarking on the concept to study the potential of circulatory concentrations of adenosine and ATP and their metabolites as biomarkers for cardiovascular protection and as targets for anti-ischemia drugs $[3,4]$. The importance of adenosine and ATP in regulating many biological functions has long been recognized, especially for their effects on the cardiovascular system $[5,6]$. It is known that adenosine and ATP are key factors in regulation of coronary blood flow [7], inhibiting platelet aggregation [8], protection of myocardium [9], neuromodulation [10], attenuating tissue necrosis [6], ischemic preconditioning [11], immunomodulation [12], energy metabolism [13], and pain mediation [14] which together maintain the homeostasis of the cardiovascular system. It has been shown that patients with effort angina and essential hypertension have altered adenosine metabolism compared to healthy individuals [15], and that plasma concentration of adenosine increase in patients with Congestive Heart Failure (CHF) [16], which could be a physiologic response to heart failure and help to reduce the severity of the disease [17]. Thus it has been postulated that adenosine and ATP may be used as sensitive biomarkers to quantify myocardial and endothelial ischemia [18], and for monitoring therapeutic effects of anti-ischemia drugs $[19,20]$.

In response to ischemia, ATP is broken down to release adenosine. The activity of adenosine is very short lived because it is rapidly taken up by myocardial and endothelial cells, erythrocytes (RBC), and also rapidly metabolized to inosine and subsequently to hypoxanthine, adenine, S-Adenosyl Homocysteine (SAH), and other adenine nucleotides [15]. There are also evidences to indicate that ATP is a neurotransmitter and released together with adenosine to maintain the homeostasis within the cardiovascular system and for neuroprotection [21]. Extracellular ATP is broken down rapidly to ADP and AMP and finally to adenosine by 5 '-nucleotidase [15]. These metabolic events are known to occur in the myocardium as well as in erythrocytes (RBC), but it is not clear whether or not they are regulated by similar mechanism $[22,23]$.

There is a host of evidence to indicate that many clinically useful therapeutic agents act by altering the normal physiologic functions of adenosine [24]. For example, dipyridamole exerts its vasodilating effect by inhibiting the uptake of endogenous adenosine thereby prolonging its effect in the circulation $[25,26]$. On the other hand, theophylline and the methylxanthines are competitive inhibitors of adenosine binding to its receptors and hence they antagonize the effects of adenosine and dipyridamole [24]. Adenosine and ATP and their association with energy metabolism are increasingly exploited as targets for drug discovery and development for a wide variety of clinical conditions [27]. For example, adenosine A2A receptor agonists are currently developed as anti-inflammatory agents or for stress test [28], the P2Y12 receptor antagonists for coronary artery disease [29], and the A1 receptor agonists and P2X7 antagonists have potential for cardiovascular and neuroprotection [30]. There are now also evidences both from our laboratory and others to indicate that while many cardiovascular drugs such as nucleoside transport inhibitors, calcium antagonists (CCBs), sotalol, and amiodarone inhibit the uptake of adenosine, others such as propranolol and enalapril are practically devoid of any inhibitory activity $[19,31]$. Thus adenosine and ATP transport and metabolism are clinically relevant therapeutic targets for cardiovascular and neuroprotective agents $[30,32,33]$.

In summary, ATP and adenosine metabolism are key regulators affecting cardiovascular homeostasis. They could be exploited as biomarker targets for drug development and management of cardiovascular diseases which have affected millions of patients worldwide.

\section{References}

1. Roger VL, Go AS, Lloyd-Jones DM, Adams RJ, Berry JD, et al. (2011) Heart disease and stroke statistics--2011 update: a report from the American Heart Association. Circulation 123: e18-18e209.

2. Go AS, Mozaffarian D, Roger VL, Benjamin EJ, Berry JD, et al. (2013) Heart disease and stroke statistics--2013 update: a report from the American Heart Association. Circulation 127: e6-6e245.

3. Yeung PK, Dauphinee J, Marcoux T (2013) Effect of acute exercise on cardiovascular hemodynamic and red blood cell concentrations of purine nucleotides in hypertensive compared with normotensives rats. Ther Adv Cardiovasc Dis 7: 63-74.

4. Yeung PK, Seto D (2013) A study of the effect of isoproterenol on red blood cell concentrations of adenine nucleotides in a freely moving rat model in vivo. Cardiol Pharmacol 2: 102.

5. Ely SW, Berne RM (1992) Protective effects of adenosine in myocardial ischemia. Circulation 85: 893-904.

6. Burnstock G (2002) Purinergic signaling and vascular cell proliferation and death. Arterioscler Thromb Vasc Biol 22: 364-373.

*Corresponding author: Pollen K Yeung, Dalhousie University, Halifax, NS Canada, Tel: 902-494-3845; Fax: 902-494-1396;E-mail: Pollen.Yeung@Dal.Ca

Received August 29, 2013; Accepted August 29, 2013; Published September 04, 2013

Citation: Yeung PK (2013) ATP Metabolism as Biomarker Target for Cardiovascular Protection. Cardiol Pharmacol 2: e118. doi:10.4172/2329-6607.1000e118

Copyright: (c) 2013 Yeung PK. This is an open-access article distributed unde the terms of the Creative Commons Attribution License, which permits unrestricted use, distribution, and reproduction in any medium, provided the original author and source are credited. 
Citation: Yeung PK (2013) ATP Metabolism as Biomarker Target for Cardiovascular Protection. Cardiol Pharmacol 2: e118. doi:10.4172/2329$6607.1000 \mathrm{e} 118$

7. Berne RM (1980) The role of adenosine in the regulation of coronary blood flow. Circ Res 47: 807-813.

8. Gerlach E, Becker BF, Nees S (1987) Formation of adenosine by vascular endothelium: a homeostatic and antithrombogenic mechanism? Topics and Perspectives in Adenosine Research 309-320.

9. Cohen MV, Downey JM (2008) Adenosine: trigger and mediator of cardioprotection. Basic Res Cardiol 103: 203-215.

10. Burnstock G (2009) Purines and sensory nerves. Handb Exp Pharmacol 333392.

11. Das M, Das DK (2008) Molecular mechanism of preconditioning. IUBMB Life 60: 199-203.

12. McCallion K, Harkin DW, Gardiner KR (2004) Role of adenosine in immunomodulation: review of the literature. Crit Care Med 32: 273-277.

13. Ingwall JS (2009) Energy metabolism in heart failure and remodelling Cardiovasc Res 81: 412-419.

14. Burnstock $G$ (2012) Targeting the visceral purinergic system for pain control. Curr Opin Pharmacol 12: 80-86.

15. Yeung PK, Buckley SJ, Hung OR, Pollak PT, Barclay KD, et al. (1997) Effect of diltiazem on plasma concentrations of oxypurines and uric acid. Ther Drug Monit 19: 286-291.

16. Funaya H, Kitakaze M, Node K, Minamino T, Komamura K, et al. (1997) Plasma adenosine levels increase in patients with chronic heart failure. Circulation 95: 1363-1365.

17. Kitakaze M, Minamino T, Node K, Koretsune Y, Komamura K, et al. (1998) Elevation of plasma adenosine levels may attenuate the severity of chronic heart failure. Cardiovasc Drugs Ther 12: 307-309.

18. Rounds S, Hsieh L, Agarwal KC (1994) Effects of endotoxin injury on endothelial cell adenosine metabolism. J Lab Clin Med 123: 309-317.

19. Yeung PK, Mosher SJ, Li R, Farmer PS, Klassen GA, et al. (1993) Erythrocyte adenosine transport. A rapid screening test for cardiovascular drugs. J Pharmacol Toxicol Methods 30: 163-167.

20. Yeung PK, Dauphinee J, Simonson K, Gouzoules T (2009) RBC concentrations of ATP as potential in vivo biomarkers for cardiovascular safety of antihypertensive agents in rats. Clin Pharmacol Ther 85 (Suppl 1): S70.

21. Burnstock G (2009) Purinergic signalling: past, present and future. Braz J Med Biol Res 42: 3-8.
22. Plagemann PG, Wohlhueter RM, Kraupp M (1985) Adenosine uptake, transport, and metabolism in human erythrocytes. J Cell Physiol 125: 330-336.

23. Van Belle H (1993) Nucleoside transport inhibition: a therapeutic approach to cardioprotection via adenosine? Cardiovasc Res 27: 68-76.

24. Clanachan AS, Heaton TP, Parkinson FE (1987) Drug interactions with nucleoside transport systems. Topics and Perspectives in Adenosine Research $118-130$

25. Belloni FL, Hintze TH (1987) Effects of adenosine on the heart rate in conscious animals: interaction between adenosine and parasympathetic mechanisms at the sinoatrial node. Prog Clin Biol Res 230: 361-374.

26. Conradson TB, Dixon CM, Clarke B, Barnes PJ (1987) Cardiovascular effects of infused adenosine in man: potentiation by dipyridamole. Acta Physiol Scand 129: 387-391.

27. Gomes CV, Kaster MP, Tomé AR, Agostinho PM, Cunha RA (2011) Adenosine receptors and brain diseases: neuroprotection and neurodegeneration. Biochim Biophys Acta 1808: 1380-1399.

28. Gemignani AS, Abbott BG (2010) The emerging role of the selective A2A agonist in pharmacologic stress testing. J Nucl Cardiol 17: 494-497.

29. Oliphant CS, Doby JB, Blade CL, Das K, Mukherjee D, et al. (2010) Emerging P2Y12 receptor antagonists: role in coronary artery disease. Curr Vasc Pharmacol 8: 93-101.

30. Romagnoli R, Baraldi PG, Tabrizi MA, Gessi S, Borea PA, et al. (2010) Allosteric enhancers of $A 1$ adenosine receptors: state of the art and new horizons for drug development. Curr Med Chem 17: 3488-3502.

31. Fredholm BB, Lindström K, Wallman-Johansson A (1994) Propentofylline and other adenosine transport inhibitors increase the efflux of adenosine following electrical or metabolic stimulation of rat hippocampal slices. J Neurochem 62 : 563-573.

32. Beadle RM, Frenneaux M (2010) Modification of myocardial substrate utilisation: a new therapeutic paradigm in cardiovascular disease. Heart 96 824-830.

33. Scolletta S, Biagioli B (2010) Energetic myocardial metabolism and oxidative stress: let's make them our friends in the fight against heart failure. Biomed Pharmacother 64: 203-207. 